\title{
Trends in Subjective Income Poverty Rates in the European Union
}

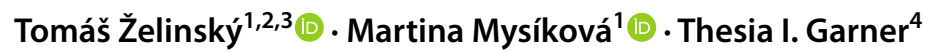

Accepted: 5 August 2021 / Published online: 21 September 2021

(c) The Author(s) 2021

\begin{abstract}
When developing anti-poverty policies, policymakers need accurate data on the prevalence of poverty. In this paper, we focus on subjective poverty, a concept which has been largely neglected in the literature, though it remains a conceptually appealing way to define poverty. The primary goal of this study is to re-examine the concept of subjective poverty measurement and to estimate trends in subjective income poverty rates in the European Union. Our estimations are based on a Minimum Income Question using data from a representative survey, EU-SILC. We find robust empirical evidence of decreasing trends in subjective poverty in 16 of 28 EU countries. We conjecture that trends in subjective poverty may reflect changes in societies which are not captured by official poverty indicators, and our results thus enrich the existing data on general poverty trends in the EU.
\end{abstract}

Keywords Subjective poverty · Minimum income question · Intersection approach · EU-SILC · European Union

\section{Résumé}

Lors de l'élaboration des politiques de lutte contre la pauvreté, les décideurs ont besoin de données précises sur la prévalence de la pauvreté. Dans cet article, nous nous concentrons sur la pauvreté subjective, un concept qui a été largement négligé

Tomáš Želinský

tomas.zelinsky@tuke.sk

Martina Mysíková

martina.mysikova@soc.cas.cz

Thesia I. Garner

Garner.Thesia@bls.gov

1 Institute of Sociology, Czech Academy of Sciences, Jilská 1, 11000 Prague, Czech Republic

2 Faculty of Economics, Technical University of Košice, Němcovej 32, Kosice, Slovakia

3 School of Education, Durham University, Leazes Road, Durham DH1 1TA, UK

4 U. S. Bureau of Labor Statistics, 2 Massachusetts Avenue NE, Washington, DC 20212-0001, USA 
dans la littérature, bien qu'intéressant pour définir la pauvreté. L'objectif principal de cette étude est de réexaminer le concept de mesure subjective de la pauvreté et d'estimer les tendances des taux de pauvreté monétaire subjective dans l'Union européenne. Nos estimations sont basées sur une question relative au revenu minimum en utilisant les données d'une enquête représentative, EU-SILC. Nous trouvons des preuves empiriques solides que la pauvreté subjective a tendance à baisser dans 16 des 28 pays de l'UE. Nous supposons que les tendances de la pauvreté subjective peuvent refléter des changements sociétaux qui ne sont pas pris en compte par les indicateurs officiels sur la pauvreté. Ainsi, nos résultats viennent enrichir les données existantes sur les tendances générales de la pauvreté dans l'UE.

\section{Introduction}

Identifying patterns in the development of crucial socio-economic indicators is a challenging task, and the ways such developments are presented can influence policies and public opinion. There have long been discussions among researchers and practitioners on different dimensions of the quality of life. As noted by Stiglitz et al. (2009, p. 15), "objective and subjective dimensions of well-being are both important". Most empirical studies operationalise well-being using indicators of happiness or life satisfaction (see, e.g. Diener et al. 1999). The broad nature of overall life satisfaction/happiness reflects "people's self-evaluation of their lives or feelings pertaining to their emotional state" (Wong et al. 2006, p. 409), while individual satisfaction domains relate to perceived satisfaction with different life aspects including health, financial situation, and jobs (van Praag et al. 2003, p. 30). In this work, we narrow the perspective to an economic dimension of subjective well-being-subjective perceptions of poverty-which is often neglected when social policies are developed.

Clearly, tracking the socio-economic progress of a society requires tracking developments in poverty levels. Different poverty indicators (see an excellent review by Ravallion 2016) have been utilised and communicated, though a few specific poverty indices are most frequently chosen. Different conceptualisations of poverty measurements can lead to different conclusions, which are sometimes contradictory. Numerous alternative poverty measures have been developed, some of which feature useful properties (see, e.g. Foster et al. 2010; Chakravarty and Silber 2008). Nevertheless, the income poverty headcount ratio remains the most frequently communicated, primarily due to its simplicity and straightforwardness.

The Europe 2020 headline indicators, which aim to track trends in poverty and social exclusion in the European Union, include three indicators: at risk of poverty, severe material deprivation, and very low work intensity (and their aggregated version, which is the indicator at risk of poverty or social exclusion). A key target related to the "Inclusive growth" priority, as defined by the strategy: "[t]he number of Europeans living below the national poverty lines should be reduced by 25\%, lifting over 20 million people out of poverty" (European Commission 2010, p. 11), is based on a relative income poverty measure. However, the alternative specification of the target, framed as "promoting social inclusion, in particular through the 
reduction of poverty, by aiming to lift at least 20 million people out of the risk of poverty and exclusion" (European Council 2010, p. 12), is based on a multidimensional indicator of poverty. Eurostat has recently introduced "experimental" statistics demonstrating links between household income, consumption, and wealth. However, even this new measure ignores the subjective dimensions of well-being.

One of the main concerns related to the subjective approach is its inherent "subjectivity" - the trustworthiness of respondents' responses. This has also led to economists' scepticism of subjective variables (Bertrand and Mullainathan 2001), which are sometimes considered unreliable or unrealistic (Lane 1991; Vogel 2002). Nevertheless, scepticism towards subjective data seems to be lessening (Deaton and Stone 2013). Overall, subjective approaches remain relatively uncommon within the concepts of welfare measurement, though they remain a conceptually appealing way to define poverty (Ravallion 2014). In line with recommendations by Stiglitz et al. (2009), we posit that examining trends in subjective income poverty provides a useful perspective in addition to measurements of trends in official poverty statistics. Combining objective and subjective dimensions can offer better overall insights into the well-being of citizens.

Although subjective measures of poverty gained some attention in the 1980s and 1990s (van Praag et al. 1982; Danziger et al. 1984; Colosanto et al. 1984; Hagenaars and de Vos 1988; Deleeck and van den Bosch 1992; Muffels et al. 1992), they have taken a backseat in more recent years. Today, subjective measures have again begun to attract the attention of international researchers (Bishop et al. 2014; Mysíková et al. 2019, 2021; Chan and Wong 2020; Wang et al. 2020). Nevertheless, compared to objective measures of poverty, subjective poverty is understudied in the European Union in official statistics and in academic research. This suggests that people's perceptions of their economic well-being are relatively unconsidered in policy development. However, we argue that the perceptions of the poor are an essential component of the complex perspective of a country's poverty profile, and ultimately are an essential element in the formation of social policies (Veenhoven 2002). We believe that subjective concepts are an important complement to the relative income poverty and material deprivation indicators currently used in the EU. This study contributes to the empirical literature on poverty trends in the EU by presenting recent findings on trends in subjective income poverty.

The EU is one of the most highly developed regions in the world, with an economy accounting for approximately $17.8 \%$ of global GDP, according to 2019 World Bank data. ${ }^{1}$ Yet the EU is a union of heterogeneous countries with annual GDP per capita (PPP, current international dollars, 2019) ranging widely between 24,561 (Bulgaria) to 121,293 (Luxembourg). According to official 2019 statistics, the income poverty rate ranges between $10.1 \%$ (Czechia) and $24.5 \%$ (Romania); severe material deprivation rates between $1.3 \%$ (Luxembourg) and 20.9\% (Bulgaria); and the aggregate indicator of at risk of poverty or social exclusion rate varies between $12.5 \%$ (Czechia) and $32.8 \%$ (Bulgaria). ${ }^{2}$

\footnotetext{
1 World Development Indicators databank.

${ }^{2}$ Eurostat database data.
} 
The estimations performed in this study are based on an official micro-dataset of EU-SILC survey responses (European Union Statistics on Income and Living Conditions) provided for research purposes by Eurostat. The dataset contains a Minimum Income Question (MIQ), which is a typical way to operationalise "inherently subjective judgments people make about what constitutes a socially acceptable minimum standard of living in a particular society" (Ravallion 1992, p. 33). In the EU-SILC survey, the MIQ is framed as follows: "In your opinion, what is the very lowest net monthly income that your household would have to have in order to make ends meet, that is to pay its usual necessary expenses? Please answer in relation to the present circumstances of your household, and what you consider to be usual necessary expenses (to make ends meet)".

To identify subjectively poor households, we utilise a traditional intersection approach (Goedhart et al. 1977) employing control variables (for example, see de Vos and Garner 1991; Garner and Short 2004). In addition to this approach based on estimating subjective poverty thresholds for different subpopulations, we use predicted minimum incomes to calculate subjective poverty rates for the whole population. Comparing households' predicted incomes to their actual incomes allows us to directly identify each household as either subjectively poor or non-poor. This 'shortcut' is particularly useful in empirical estimations that do not require explicit values of poverty lines for different subpopulations, yet include all control variables in the estimation.

The primary goal of this study is to re-examine the concept of subjective income poverty measurement and to estimate trends in subjective income poverty rates in the EU. We find that the lowest levels of subjective income poverty are reported in Northern Europe, while the highest occur in the East and South. We further identify decreasing trends in subjective poverty (from the perspective of the main three Foster-Greer-Thorbecke (FGT) family of poverty metrics) levels in 16 out of 28 countries, and find an increasing trend only in Luxembourg.

\section{Estimating Subjective Income Poverty}

Measurements of subjective poverty are based on an assumption that "individuals themselves are the best judges of their own situation" (Flik and van Praag 1991, p. 313). The concept of estimating subjective income poverty lines was introduced to economics literature in a seminal study by Goedhart et al. (1977). The original idea was based on the Income Evaluation Question (IEQ), which asks respondents to report what they consider to be bad/sufficient/good income, in their circumstances. These data were used to estimate the so-called individual welfare function of income (van Praag 1968). The Minimum Income Question, in which respondents report the amount of income they consider minimal, is a special case of the IEQ. The IEQ and MIQ have been adopted to estimate the Leyden poverty line and the subjective poverty line (Kapteyn et al. 1988), respectively; these are both money-metrics of subjective welfare. MIQ has also been used for non-model-based evaluations of subjective income poverty, where the "individual method" (Vrooman 2009) simply relates households' actual income to the minimum income. Designating households with actual income lower than a certain multiple 
of the minimum income to be "poor" is rather arbitrary, and together with the relatively high variance of minimum income responses makes non-model-based measures less reliable.

Another approach to analyses of subjective income poverty is based on qualitative categories, including questions such as the economic ladder question (e.g.: "On which step-poorest people on the first step, rich people on the last-are you today?”), or the "Deleeck" attitude question (e.g.: "Can you make ends meet with the actual income of your household with great difficulty/some difficulty/difficulty/fairly easily/easily/very easily?") (Ravallion 2014; Pradhan and Ravallion 2000; Flik and van Praag 1991).

An important limitation of the adoption of any particular subjective poverty analysis is the availability of data. Since our aim is to estimate trends in subjective poverty in the European Union, we rely on available and comparable datasets, primarily the EU-SILC survey. This dataset contains the Minimum Income Question and the multi-level attitude "Deleeck" attitude question.

The Deleeck question was introduced by Professor Deleeck, who led research by the Centre for Social Policy (CSP) into poverty measures. The "CSP measure" is based on the subjective poverty line (SPL) approach and uses the MIQ, with the difference that only a subsample of respondents who claimed "some difficulty" to make ends meet is applied to derive the SPL. Flik and van Praag (1991) criticise the CSP measure for its strong assumption that "the level of the poverty line must be fixed by people who are on the margin of poverty and consequently have first-hand knowledge of the situation" (p. 322), in line with the original Goedhart et al. (1977) claim that "we need all observations in order to find out which people's opinion on minimum income we should honor" (p. 514). Some studies (e.g. Saunders et al. 1994) use the CSP sample-limited approach as a robustness check for SPL estimations.

Another way to utilise the Deleeck question is to simply and directly utilise the self-reported categories of difficulties of making ends meet. Deciding which categories are assumed to be "poor" becomes a relatively arbitrary choice by a researcher. For instance, Mysíková et al. (2019) consider households reporting that they are in the worst category (great difficulty to make ends meet) as subjectively poor households, in a study tracking changes in subjective perceptions of poverty in Czechia and Slovakia. This work also devotes a discussion to differences and overlaps with the responses to the MIQ. Želinský et al. (2020) further utilise the Deeleck question and the Youden index to estimate income subjective poverty lines in the EU. Responses to the question also often serve as a dependent variable in studies searching for determinants of difficulties to make ends meet (e.g. Cracolici et al. 2012). We use the MIQ and the associated intersection methodology as the central techniques in this paper.

\section{Data and Methods}

\section{The Intersection Approach}

The logic behind the intersection approach is demonstrated in Fig. 1, in which each point $[x ; y]$ represents a combination of the $\log$ of actual income $(x=\log \tilde{x})$ and the 


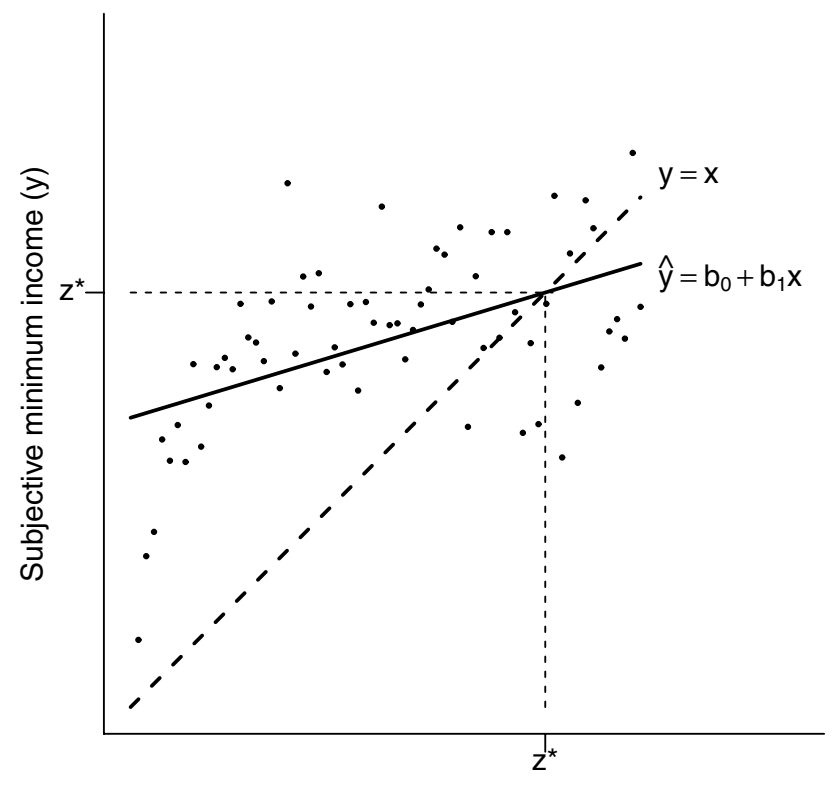

Actual income $(x)$

Fig. 1 MIQ and the intersection method (in Log form). Notes: Each point represents a combination of the $\log$ of actual $(x)$ and the $\log$ of subjective minimum $(y)$ income. $\hat{y}$ represents the estimated function of the $\log$ of subjective minimum income regressed on the log of actual income. $z^{*}$ is the log of the estimated subjective poverty line

$\log$ of subjective minimum income $(y=\log \tilde{y})$ reported in response to the Minimum Income Question. ${ }^{3}$ In this model, minimum income is envisioned as an increasing function of actual income; in empirical applications it is assumed to be increasing, and is a concave function: see de Vos and Garner (1991, p. 269).

Line

$$
\hat{y}=b_{0}+b_{1} x \text {, with } 0<b_{1}<1 \text { and } b_{0}>0,
$$

represents the estimated function describing the relationship between subjective minimum and actual income, and line $y=x$ represents equal subjective minimum and actual income. As suggested by the original approach (Goedhart et al. 1977), the subjective poverty line $\left(z^{*}\right)$ is defined as the point at which the two lines intersect: $\hat{y}=y$.

The subjective poverty line is then defined as

$$
z^{*}=\frac{b_{0}}{1-b_{1}},
$$

\footnotetext{
${ }^{3}$ For the sake of simplicity, to describe the method, we adopt the standard approach—using natural logarithms of actual and subjective minimum income $(x=\ln \tilde{x} \& y=\ln \tilde{y} ; \tilde{x}>0 \& \tilde{y}>0)$.
} 


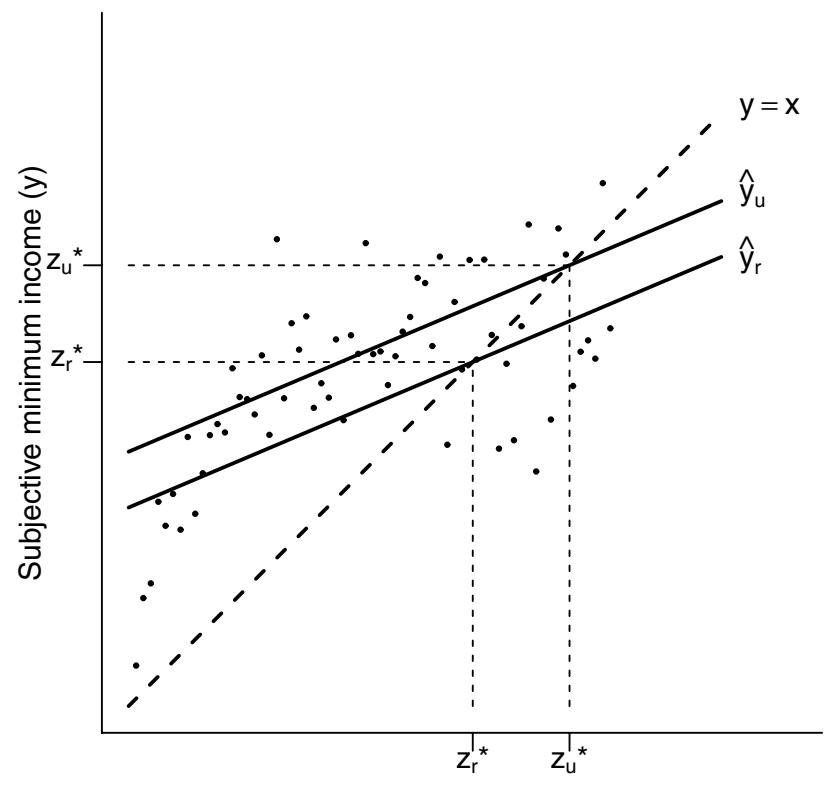

Actual income $(x)$

Fig. 2 Estimation of two alternative thresholds (in $\log$ form)

and a household $i$ is identified as subjectively poor if the following inequality holds:

$$
x_{i}<z^{*} .
$$

Employing control variables in Eq. (1) we obtain the following:

$$
\hat{y}=b_{0}+b_{1} x+\sum_{k=1}^{K} \delta_{k} v_{k}, 0<b_{1}<1,
$$

where $v_{k}, k=1, \ldots, K$ are control variables with associated estimated coefficients $\delta_{k}$, $k=1, \ldots, K$. The estimated subjective poverty line is then estimated as

$$
z^{*}=\frac{b_{0}+\sum_{k=1}^{K} \delta_{k} v_{k}}{1-b_{1}} .
$$

For instance, assuming a model with one (dichotomous) control variable (a household located in either an urban or rural area), we would obtain two different subjective poverty lines, as illustrated in Fig. 2, in which $z_{r}^{*}$ and $z_{u}^{*}$ are subjective poverty lines for households located in rural (urban) areas.

Employing control variables in Eq. (4) enables us to identify possible subjective poverty lines for numerous household characteristics. The traditional approach proposes two ways to calculate subjective poverty thresholds (Garner and Short 2004), 
also referred to as social subjective poverty lines (Ravallion 2016), to emphasise that they represent a poverty line for a whole society (or a subpopulation), not just for an individual. The first way identifies a specific threshold for each household and then finds the average (median) threshold using population weights. The second method calculates a set of thresholds differentiated by the variables defining subpopulations of interest, holding the values of control variables at their national averages. To identify social subjective poverty lines (SSPLs), we adopt the former approach, identifying an individual SPL for each household and then determining the medians of individual poverty lines across all households. We report SSPLs for different subpopulations over selected time periods.

Further, for $0<b_{1}<1$ and $b_{0}>0$ the Inequality (3) is equivalent to

$$
x_{i}<\hat{y}_{i} \text {. }
$$

It can easily be shown that, for $0<b_{1}<1$ and $b_{0}>0$, inequalities (3) and (6) are also equivalent for models employing a set of control variables. This is particularly useful in applications aimed at identifying the subjectively poor, as it is not necessary to explicitly express the subjective poverty threshold (or a set of thresholds for different subpopulations).

Ultimately, equation

$$
\hat{y}_{i}=b_{0}+b_{1} x_{i}+\sum_{k=1}^{K} \delta_{k} v_{k i}, 0<b_{1}<1
$$

can also be thought of as the minimum required income "imputed" to household $i$ based on its actual characteristics (including income). Put differently, for the given set of characteristics of household $i$, Eq. (7) expresses the minimum income required, on average, by other households with the same set of characteristics.

\section{Data and Variables}

As noted, we adopt an approach that employs control variables (Eq. 7) as suggested, e.g. by De Vos and Garner (1991). The logic behind this approach is straightforward-people's perceptions of their minimum required household income are not solely based on their actual income, but also on the characteristics of their household.

The analyses in this study are based on subsamples of EU member states' EUSILC 2004-2019 household survey microdata (Cross UDB, 2020-09 version). Following the Eurostat methodology, the resulting shares of subjectively poor households are expressed in terms of individuals. Sample sizes vary between 3143 (Cyprus, 2009) and 24,305 (Greece, 2018) observations.

The left-hand side variables in Eq. (7) are the responses to the MIQ framed in the EU-SILC survey as follows: "In your opinion, what is the very lowest net monthly income that your household would have to have in order to make ends meet, that is to pay its usual necessary expenses? Please answer in relation to the present 
circumstances of your household, and what you consider to be usual necessary expenses (to make ends meet)" [EU-SILC variable HS130].

In addition to household size, we control for numerous other household-level characteristics:

- Type of ownership of the dwelling categories include 1. outright owners, plus households with accommodation provided for free; 2 . owners paying a mortgage; 3. tenants paying either full market or reduced rent;

- Size of the flat/house measured by the number of habitable rooms per household;

- Degree of urbanisation 1. densely populated area (cities); 2. intermediate area (towns); 3. thinly populated area (rural);

- Share of market income in total household income defined as the share of total disposable household income before social transfers (before retirement and survivor's benefits) on total disposable household income.

Also, we control for individual-level characteristics, capturing the composition of adults aged $16+$ in the household:

- share of adult females,

- share of adults with tertiary education,

- share of younger adults (aged 16-30),

- migrant origin (a dummy variable indicating whether at least one adult household member was born in a different country than the country in which the survey was conducted).

In addition to the main model specification with the share of market income in total household income variable, we also estimate alternative specifications with a share of currently working adults variable. Comparing the main results (subjective poverty indices), we find that the estimates differ, on average, by approximately $1.4 \%$ for the poverty headcount index, $1.3 \%$ for the poverty gap index, and $0.1 \%$ for the poverty severity index, suggesting a relatively high level of robustness of the results.

As the data have been gathered over a relatively long time-span (2004-2019), certain variables have undergone modifications; this should be kept in mind. The type of ownership of dwelling [variable HH020/HH021: Tenure status] did not contain the category "owners paying a mortgage" before 2010. We therefore created a category defined as "owners paying interest repayments on a mortgage" [variable HY100G/HY100N]. ${ }^{4}$ The highest number of missing values in the dependent variable is in the UK (46\% in 2017 and 37\% in 2018). High numbers of missing

\footnotetext{
${ }^{4}$ However, the variable HY100G/HY100N, together with a few other income components, was only mandatory from 2007. In cases where these values are missing (Austria, Greece, Spain, Italy, Luxembourg, Portugal: 2004-2006; Cyprus, Latvia: 2005-2006; France 2004), we use the original categories (excluding "owners paying mortgages"). Nevertheless, when we compare results based on models with tenure status distinguishing between owners repaying a mortgage or not, households identified as subjectively poor remain unchanged.
} 


\section{HU, FGT.0}

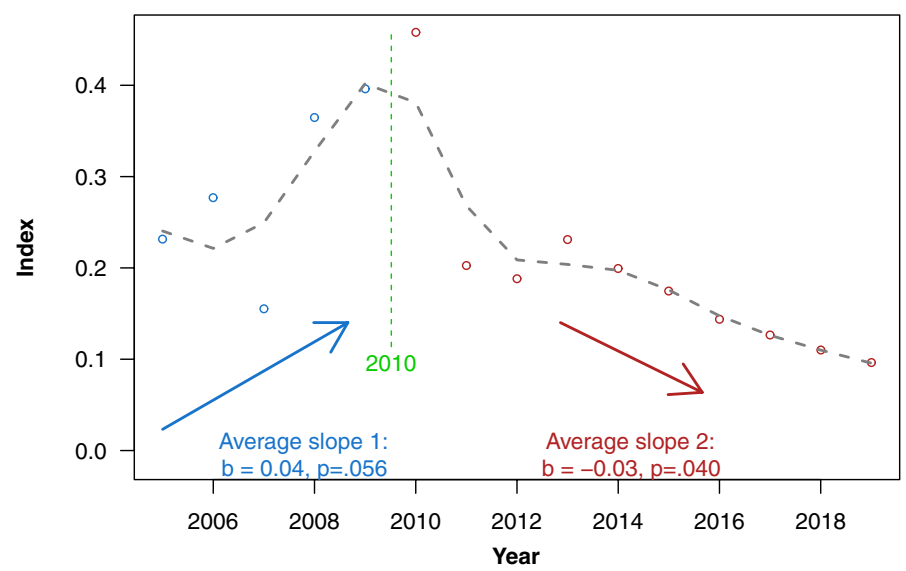

Fig. 3 An illustration of the identification of a U-shaped trend (data on Hungary). Source EU-SILC 2005-2019. Authors' computations

values also occur in the data for the Netherlands (17-30\%) and Sweden (23-34\%). Values are completely missing for the degree of urbanisation in certain countries and years (Germany: 2015-2019; Malta: 2007-2008; Netherlands: 2005-2019; Slovenia: 2005-2019), while for Estonia and Latvia, only two categories are reported (densely/thinly populated areas).

\section{Identification of Trends in the Subjective Poverty Rates}

In addition to estimating the FGT measures (Foster et al. 1984) of subjective income poverty across EU member states, we aim to identify patterns in the developments of the indices over time. Although the time-span is relatively long (15-16 years in most cases), from the perspective of a rigorous time series analysis, this may be seen as somewhat short. We take this into consideration when interpreting the results of our trend analyses.

We examine whether developments in subjective income poverty trends suggest the presence of one of three alternatives: 1. a linear trend; 2. a U-shaped or an inverted-U trend; or 3. neither of these. Assessment of linear trends is based on estimating the coefficients of a linear trend function, whereas the presence of statistically significant coefficients associated with the linear term suggests a linear trend. When assessing the U-shaped trend, we do not rely on the traditional approach of testing the U-shaped relationship via quadratic regression (as statistical significance of both linear and quadratic terms does not necessarily imply a U-shaped curve). Instead, we follow the approach introduced by Simonsohn (2018), which proposes estimating a regression with two separate lines, one for "low" and one for "high" values of $x$ with a break-point set using the Robin Hood algorithm (illustrated in Fig. 3). A U-shaped curve is present if the two slopes are of opposite signs and, at the same time, are individually statistically significant. 


\section{Results}

We present the main results in two sections: estimations of social subjective poverty lines and FGT-class poverty indices (reported in \%), and trends in subjective poverty. We report the main results on trends in subjective poverty indicators over the whole period for which data were available, along with estimations of social subjective poverty lines for the most recent period (2019) in Table 1. Detailed country profiles including estimates of subjective poverty indices and poverty lines over all periods are reported in the Supplementary Materials.

\section{Social Subjective Poverty Lines}

As outlined in the methodological section, our primary results are based on models with control variables. Adopting this approach, we estimate SSPLs for different subpopulations. Since our aim is not to conduct cross-country comparisons, although we comment on subjective poverty statistics in individual countries, we do not use the PPS EUR exchange rate; the estimations are reported in EUR. Results in Table 1 refer to the most recent available data (2019 in most cases, but 2018 for a small number of countries) and are reported in current prices.

The estimates of poverty lines for the years 2004 to 2019 reported in the Supplementary Materials are reported in constant 2015 euros (real terms), adjusted for inflation by adopting harmonised indices of consumer prices (HICP). A similar approach is used by Eurostat, e.g. when reporting the at-risk-of-poverty rate anchored at a fixed moment in time (European Commission 2020). We report SSPLs for different types of households based on ownership status, degree of urbanisation, and household type (member structure).

The relative income poverty line for a single adult household is the information most often reported in other studies and official documents. ${ }^{5}$ We compare social subjective poverty lines to official relative income poverty lines for such households, and find that subjective poverty lines are on average $50 \%$ higher than the official ones. However, there is large variation in the data, with ratios of the subjective to official income poverty lines ranging from 0.75 (Finland and the UK) to above 3 (Greece, Romania, Bulgaria). In addition to SSPLs reported for single adult households, we report SSPLs for households with two adults and two children as a proxy for a "typical" household with children, though it is difficult to unambiguously define a "typical household". Again, comparing subjective to official income poverty lines results in ratios ranging from 0.65 (the Netherlands) to 3.5 (Bulgaria).

\footnotetext{
5 The relative income poverty approach considers equivalised income, which refers to individual equivalent income. Using the OECD-modified equivalence scale, an individual equivalent income corresponds to total household income only in single-adult households. Similarly, the official relative income poverty line is directly comparable to the total household income of singles, while the line for other household types can be derived as a multiple of the official line.
} 
Table 1 Trends in subjective poverty indicators and selected 2019 results

\begin{tabular}{|c|c|c|c|c|c|c|c|}
\hline \multirow[t]{3}{*}{ Country } & \multicolumn{7}{|c|}{ Subjective poverty indices } \\
\hline & \multicolumn{3}{|l|}{ Trend } & \multirow[b]{2}{*}{$T$} & \multicolumn{3}{|c|}{ Index value } \\
\hline & $F G T_{0}$ & $F G T_{1}$ & $F G T_{2}$ & & $F G T_{0}$ & $F G T_{1}$ & $F G T_{2}$ \\
\hline Austria & None & None & None & 16 & 8.1 & 2.5 & 1.4 \\
\hline Belgium & None & Decreasing ${ }^{\mathrm{b}}$ & Decreasing & 16 & 22.8 & 5.1 & 1.8 \\
\hline Bulgaria & Decreasing & Decreasing & Decreasing & 13 & 84.3 & 41.6 & 24.8 \\
\hline Croatia & Inconclusive & Inconclusive & Inconclusive & 10 & 50.4 & 16.9 & 8.1 \\
\hline Cyprus & Decreasing & Decreasing & Decreasing & 15 & 17.5 & 3.3 & 1.0 \\
\hline Czechia & Decreasing & Decreasing & Decreasing & 15 & 9.6 & 1.9 & 0.7 \\
\hline Denmark & None & None & Inv-U $\mathrm{U}^{\mathrm{b}}[2015]$ & 16 & 4.5 & 1.2 & 0.5 \\
\hline Estonia & Decreasing & Decreasing & Decreasing & 15 & 48.9 & 14.9 & 6.5 \\
\hline Finland & Decreasing & Decreasing & Decreasing & 16 & 2.0 & 0.5 & 0.3 \\
\hline France & Decreasing & Decreasing & Decreasing & 16 & 23.0 & 5.3 & 1.9 \\
\hline Germany & None & None & None & 15 & 13.3 & 3.5 & 1.5 \\
\hline Greece & None & None & None & 16 & 79.1 & 31.7 & 16.3 \\
\hline Hungary & Inconclusive & None & None & 15 & 9.6 & 2.8 & 1.3 \\
\hline Ireland $^{\mathrm{a}}$ & None & Inv-U $U^{b}[2013]$ & Inv-U [2013] & 15 & 4.1 & 1.1 & 0.5 \\
\hline Italy $^{a}$ & Decreasing & Decreasing & Decreasing & 15 & 24.8 & 8.3 & 4.4 \\
\hline Latvia & Decreasing & Decreasing & Decreasing & 15 & 61.2 & 22.5 & 11.3 \\
\hline Lithuania & Decreasing & Decreasing & Decreasing & 15 & 38.3 & 12.9 & 6.3 \\
\hline Luxembourg & Increasing & Increasing & Increasing & 16 & 19.6 & 5.5 & 2.6 \\
\hline Malta & Decreasing & Decreasing ${ }^{\mathrm{b}}$ & Decreasing & 13 & 8.9 & 2.1 & 0.9 \\
\hline Netherlands & Decreasing & Decreasing $^{\mathrm{b}}$ & None & 15 & 3.9 & 1.4 & 0.8 \\
\hline Poland & Decreasing & Decreasing & Decreasing & 15 & 18.9 & 5.1 & 2.2 \\
\hline Portugal & Decreasing & Decreasing & Decreasing & 16 & 13.5 & 3.9 & 1.8 \\
\hline Romania & Decreasing & Decreasing & Decreasing & 12 & 58.1 & 24.5 & 13.7 \\
\hline Slovakia & Decreasing & Decreasing & Decreasing & 15 & 28.3 & 7.6 & 3.3 \\
\hline Slovenia & None & None & None & 15 & 14.9 & 3.6 & 1.4 \\
\hline Spain & Decreasing & Decreasing & Decreasing & 16 & 33.7 & 11.2 & 5.7 \\
\hline Sweden & Decreasing & Decreasing & Decreasing & 16 & 8.0 & 2.5 & 1.4 \\
\hline $\begin{array}{l}\text { United } \\
\text { Kingdom }^{\mathrm{a}}\end{array}$ & None & None & None & 14 & 4.4 & 1.3 & 0.7 \\
\hline
\end{tabular}


Table 1 (continued)

\begin{tabular}{|c|c|c|c|c|c|c|c|c|c|c|}
\hline \multirow[t]{3}{*}{ Country } & \multicolumn{8}{|c|}{ Social subjective poverty line } & \multirow{2}{*}{\multicolumn{2}{|c|}{$\frac{\text { Official PL }}{\text { Household type }}$}} \\
\hline & \multicolumn{3}{|c|}{ Ownership of dwellings } & \multicolumn{2}{|c|}{ Urbanisation } & \multirow[b]{2}{*}{ Rural } & \multicolumn{2}{|c|}{ Household type } & & \\
\hline & Owner & Mortgage & Tenant & Cities & Towns & & $1 \mathrm{~A}$ & $2 \mathrm{~A}+2 \mathrm{~K}$ & $1 \mathrm{~A}$ & $2 \mathrm{~A}+2 \mathrm{~K}$ \\
\hline Austria & 1730 & 2361 & 1816 & 1892 & 1941 & 1932 & 1241 & 2371 & 1286 & 2702 \\
\hline Belgium & 2243 & 2986 & 2353 & 2644 & 2533 & 2712 & 1760 & 3057 & 1230 & 2584 \\
\hline Bulgaria & 1348 & 1911 & 1508 & 1375 & 1367 & 1360 & 664 & 1551 & 211 & 444 \\
\hline Croatia & 1262 & 1662 & 1145 & 1301 & 1348 & 1225 & 731 & 1432 & 365 & 767 \\
\hline Cyprus & 1626 & 2631 & 1609 & 1824 & 1873 & 1660 & 1004 & 2161 & 811 & 1703 \\
\hline Czechia & 794 & 1060 & 843 & 915 & 818 & 855 & 597 & 1036 & 500 & 1050 \\
\hline Denmark & 1800 & 2417 & 1592 & 1976 & 2062 & 1946 & 1437 & 2655 & 1536 & 3225 \\
\hline Estonia & 1613 & 2292 & 1416 & 1764 & & 1731 & 938 & 2308 & 573 & 1203 \\
\hline Finland & 984 & 1668 & 1207 & 1401 & 1359 & 1231 & 935 & 1700 & 1244 & 2612 \\
\hline France & 2016 & 3014 & 2175 & 2516 & 2376 & 2279 & 1627 & 2974 & 1128 & 2369 \\
\hline Germany & 1711 & 2566 & 1736 & & & & 1383 & 2531 & 1176 & 2469 \\
\hline Greece & 1972 & 2375 & 1886 & 2031 & 2081 & 1904 & 1298 & 2251 & 410 & 861 \\
\hline Hungary & 466 & 551 & 460 & 507 & 473 & 457 & 346 & 547 & 293 & 615 \\
\hline Ireland $^{\mathrm{a}}$ & 1468 & 2379 & 1618 & 1900 & 1731 & 1793 & 1239 & 2182 & 1246 & 2617 \\
\hline Italy $^{a}$ & 1675 & 2119 & 1776 & 1801 & 1746 & 1700 & 1296 & 2049 & 842 & 1769 \\
\hline Latvia & 1361 & 2122 & 1417 & 1412 & & 1561 & 800 & 1910 & 409 & 860 \\
\hline Lithuania & 926 & 1324 & 975 & 975 & 1429 & 960 & 599 & 1263 & 379 & 797 \\
\hline Luxembourg & 2644 & 4283 & 3183 & 3474 & 3675 & 3270 & 2387 & 4302 & 1818 & 3817 \\
\hline Malta & 1130 & 1907 & 1038 & 1284 & 1255 & & 876 & 1577 & 768 & 1612 \\
\hline Netherlands & 1148 & 1580 & 1196 & & & & 1123 & 1671 & 1231 & 2584 \\
\hline Poland & 810 & 1065 & 835 & 860 & 845 & 825 & 545 & 961 & 356 & 748 \\
\hline Portugal & 759 & 1124 & 874 & 990 & 888 & 805 & 609 & 1138 & 501 & 1052 \\
\hline Romania & 742 & 871 & 793 & 820 & 762 & 683 & 583 & 790 & 193 & 404 \\
\hline Slovakia & 1128 & 1286 & 1140 & 1145 & 1161 & 1170 & 694 & 1246 & 406 & 853 \\
\hline Slovenia & 1371 & 1839 & 1314 & & & & 921 & 1666 & 703 & 1477 \\
\hline Spain & 1729 & 2216 & 1930 & 1978 & 1843 & 1824 & 1373 & 2218 & 751 & 1577 \\
\hline Sweden & 1191 & 1751 & 1519 & 1660 & 1602 & 1491 & 1220 & 1972 & 1224 & 2570 \\
\hline $\begin{array}{l}\text { United } \\
\text { Kingdom }^{\mathrm{a}}\end{array}$ & 923 & 1712 & 1197 & 1321 & 1311 & 1306 & 811 & 1727 & 1073 & 2254 \\
\hline
\end{tabular}

$F G T_{0}$ : head-count index; $F G T_{1}$ : poverty gap index; $F G T_{2}$ : severity of poverty index. Subjective poverty lines and indicators reported in this table refer to the most recent available period: 2019 (if not stated otherwise). For each index, a trend over the whole period of available data is identified. "None" refers to lack of evidence for either (linear/U-shaped) trend. "Inv-U" refers to inverted U-shaped trend. "Inconclusive" refers to indicating both linear and U-shaped trends. For U-shaped curves, we also report the year of the turning point in brackets. "Official PL" refers to official relative income poverty lines reported by Eurostat. All amounts are in EUR/month (current prices). Abbreviations used for 'household type': $A=$ adult $K=$ child

${ }^{a}$ For Ireland, Italy, and the United Kingdom, 2019 data were not available, reported results are based on the most recent (2018) data

${ }^{\mathrm{b}}$ Denotes significance at 0.1 , all other reported results are significant at 0.05 level

Source: EU-SILC 2004-2019. Authors' computations 
The 2019 results further suggest that the SSPL for households paying mortgages is, on average, approximately $40 \%$ higher than for households that own their home outright. The highest differences between the two types of households are reported in the United Kingdom and Finland (85\% and 70\%, respectively), and the lowest in Slovakia, Romania, and Hungary (between $14 \%$ and 18\%). In general, the proportion is higher in Western EU countries and lower in Eastern EU countries. In most cases, SSPLs estimated for the city-type-of-dwelling are higher than those for rural areas (on average, by 6\%), with the highest differences in Portugal and Romania (23\% and 20\%, respectively). In contrast, in Latvia, SSPLs in cities are, on average, $10 \%$ lower than those in rural areas. The results further suggest a clear patternlarger household types are associated with higher SSPLs. The SSPL for a household of two adults and two children is, on average, $85 \%$ greater than the SSPL for oneperson households. The SSPL for such households in Estonia and Latvia are almost 2.5-times the value for one-person households, while in Romania, the Netherlands, Italy, and Hungary, it is only $35 \%$ to $58 \%$ greater. A break-down of results appears in Table 1, and detailed subjective poverty country profiles are reported in Supplementary Material.

\section{Trends in Subjective Poverty}

The 2019 results indicate that the lowest levels of subjective poverty are reported in Finland $\left(F G T_{0}=2.0 \% ; F G T_{1}=0.5 \% ; F G T_{2}=0.3 \%\right)$. Bulgaria and Greece have the highest levels of subjective poverty $\left(F G T_{0}\right.$ between $79 \%$ and $84 \% ; F G T_{1}$ between $32 \%$ and $42 \% ; F G T_{2}$ between $16 \%$ and $25 \%$ ).

If the subjective poverty rate is considered to be an alternative indicator for the assessment of income poverty in the EU, a legitimate question would be whether subjective poverty rates in the EU have decreased or increased over time. To answer this question, we employ a simple trend analysis assessing linear and quadratic trends of headcount $\left(F G T_{0}\right)$, poverty gap $\left(F G T_{1}\right)$, and severity of poverty indices $\left(F G T_{2}\right)$. Our results suggest a decreasing trend in all three indices in 16 of 28 countries; no common trend across all three indices was identified in five countries; and an increasing trend is present in one country.

The fastest average annual rate of decrease in the headcount index (3.6 p.p.) is reported in Slovakia (from $84.1 \%$ in 2005 to $28.3 \%$ in 2019), followed by Portugal (2.8 p.p.: from $46.5 \%$ in 2004 to $13.5 \%$ in 2019 ). Croatia also experienced substantial decreases in the headcount index; however, the overall picture is somewhat ambiguous, as the results also suggest an inverted U-shaped curve with a break-point in 2013 (see Table S.2.HR in the Supplementary Materials for further details). Slovakia and Latvia have the fastest rates of decrease in the mean poverty gap (between 1.5 and 1.6 p.p.); the fastest declines in severity of poverty are reported in Latvia and Bulgaria (1.1 and 0.9 p.p.). Conversely, increasing trends in all three indices are observed only in Luxembourg, which experienced average yearly increases of $1.1,0.3$, and 0.2 p.p. The results do not clearly suggest a U-shaped or an inverted U-shaped relationship for all three indicators for any EU country. However, as noted above, results for Croatia are inconclusive, suggesting both decreasing and inverted 
U-shaped trends. As suggested by figures reported in the country profile for Croatia, the visual representation of the relationship suggests the presence of a break-point in 2013. However, it also suggests a decreasing trend, as the values of subjective poverty indicators have been declining continuously since 2014. However, because Croatia includes only ten observations, the results should be interpreted cautiously.

During the 2004 to 2019 period, numerous important events occurred in the European Union, including adoption of the Euro currency (in Cyprus in 2008; Estonia in 2011; Latvia in 2014; Lithuania in 2015; Malta in 2008; Slovakia in 2009 and Slovenia in 2007) and the economic consequences of the Great Recession (2008-2012). It would be interesting to assess the effects of these events on subjective poverty indices. However, frequent overlaps of these and other influential events in many countries make such analyses challenging. Nevertheless, we cautiously comment on significant deviations from the primary trends in selected EU countries in line with the recession period.

Austria has experienced stable subjective poverty trends, with deviant values in 2008 and 2010. Belgium's subjective poverty indicators have been weakly decreasing with a slight deviation in 2008. On average, the general trend in subjective poverty in Cyprus has a decreasing nature, although a temporary sharp increase was reported in 2010 and 2011. A similar pattern can also be observed in Czechiaan overall decreasing trend with temporary increases in 2011 and 2012. Germany's rates decreased slightly between 2005 and 2009, followed by a weak increase between 2010 and 2014, not suggesting any consistent trend. Similar trends also occurred in Denmark, Ireland, and Estonia; there was significantly less prevalence of subjective poverty in Denmark (deviating 2009-2010) and Ireland (deviating from decreasing in 2010 but returning to further decreases after 2013), and considerably higher in Estonia with a sharp increase between 2010 and 2011.

Though the visual representation of subjective poverty indicators trends in Greece suggests a U-shaped curve with indices decreasing between 2004 and 2011 followed by growth until 2014, the trend reversed in 2015 and the values of indicators began to decline. Consequently, the trend did not suggest an unambiguous U-shaped relationship. The pattern in Hungary's subjective poverty can be considered somewhat unstable. From the perspective of the headcount index, a sharp decrease between 2006 and 2007 was followed by a severe increase in 2008 and 2010, then it dropped and continued to decrease. The poverty gap index has an overall decreasing trend (with deviations between 2008 and 2010), while the severity of poverty is rather stable, again with deviations between 2008 and 2010. The decreasing trends in Lithuania, Latvia, and Malta were interrupted by a sudden increase in Lithuania in 2011; in Latvia in 2011-2013; and in Malta in 2010. The rapid decreases in the subjective poverty indices in Slovakia were interrupted by moderate increases between 2013 and 2015, and then returned to falling. Romanian data suggest decreasing trends in subjective poverty indices. However, when performing a trend analysis on Romanian data, we excluded the subjective poverty indicators for 2010. As suggested by the country profile for Romania, the estimated 2010 social subjective poverty line is clearly an outlier (212 EUR/month for a single-adult household in 2015 prices, which is approximately half of the values reported in earlier/later periods). 
There is a question regarding to what extent the economic recession may have affected the levels of subjective poverty in the European Union. Trends in the poverty lines in the 2009-2012 period do not suggest any clear patterns. In some countries, initially increasing trends in subjective poverty lines began to stagnate, in some countries they began to decrease, and in other countries they began to increase at faster rates. Further, numerous other potentially significant events occurred around the same period, such as adoption of the Euro-currency in some countries, which makes it difficult to cleanly separate the effects of the economic crisis on subjective poverty indicators. Consequently, investigation of the true effects of the crisis on subjective poverty levels, if any, would require rigorous econometric methods, and is beyond the scope of this paper.

\section{Subjective Poverty as a Supplementary Measure to the Official Indicators}

In 2010, the European Council adopted a Europe 2020 strategy with five key objectives, including lifting at least 20 million people out of the risk of poverty and social exclusion (European Council 2010). European institutions track the progress of the main aggregate indicator of at risk of poverty or social exclusion and its individual indicators: at risk of poverty; severe material deprivation; jobless households (or those with very low work intensity). Although we believe that the current official multidimensional poverty indicator has numerous drawbacks, in this study we do not aim to challenge or criticise it. The current multidimensional indicator was suggested by the Social Protection Committee (SPC 2010) to measure the overall number of people who are at risk of poverty or excluded on the basis of the three dimensions of poverty and exclusion. The relative poverty concept, despite its numerous problematic aspects, has been adopted in the EU since the EU Council of Ministers in 1975 (Bradshaw and Mayhew 2011). When designing the multidimensional poverty indicator, several national delegations preferred an indicator based on two dimensions only (excluding joblessness), however, most of them ultimately accepted the addition of a low work intensity indicator as the third dimension. The role of this indicator is to better understand the links between poverty and labour market exclusion at the individual level. The severe material deprivation rate was meant to represent the concept of absolute poverty. The final aggregated indicator counts the share of individuals endangered in at least one dimension.

In Fig. 4, we provide a scenario of how the official poverty rates would change if we produced an indicator that includes a fourth dimension-subjective income poverty. A low increase in the value of the multidimensional indicator would suggest that subjective perceptions of poverty are already largely reflected in the three current dimensions, whereas a larger increase would suggest the opposite. Figure 4 depicts the addition of subjective poverty status to the current official indicator of multidimensional poverty in the EU. The lightest parts of the bars represent the shares of individuals who are officially poor, but not subjectively poor. The darkest parts represent shares of individuals who are subjectively poor, but not officially poor. The grey parts between light and dark parts of the bars represent the overlap, i.e. individuals who are both officially and subjectively poor. The figure suggests that the impact 
of adding subjective poverty to the current multidimensional indicator of poverty or social exclusion is rather low in Western and Northern EU countries, while it is typically larger for Eastern and Southern EU countries. The results are also stable in time, except in Portugal, Hungary, Czechia, and Slovakia where the impact of subjective poverty declined considerably between 2008 and 2019. Conversely, though inclusion of subjective poverty had a strong effect on the multidimensional indicator of poverty in Luxembourg in 2019, it had almost no effect in 2008.

\section{Discussion and Implications}

To the best of our knowledge, this is the first study to explore trends in subjective poverty in the European Union. With the exception of a few countries, all three subjective poverty indices (headcount ratio, the poverty gap index, and the severity of poverty index) show consistent decreasing trends in subjective poverty. In this study, we do not aim to compare the differences in perceptions of subjective poverty across countries, since such comparisons would be questionable due to cultural differences.

In practical applications, relative income poverty lines are most commonly used. We compare the officially reported poverty lines to social subjective poverty lines, and show that there is large variation in the differences between the two lines. For the majority of countries, subjective poverty lines are higher than official relative income poverty lines. This finding is particularly important for policy implications, as it suggests that relying on relative income poverty lines may result in underestimating poverty levels, at least in terms of public perception.

Our results further suggest that social subjective poverty lines are considerably higher for households paying mortgages and tenants paying rent than for outright homeowners. Clearly, making mortgage or rent payments is a burden for the household budget, hence such households require a higher minimum income. Similar conclusions have also been suggested by previous studies, which have found that mortgage and rental payments affect the financial satisfaction and well-being of households (Tharp et al. 2020; Gerlach-Kristen and Lyons 2018). This finding is particularly useful for designing and adjusting objective poverty measures considering housing costs, and in considerations related to imputed rent.

Our results further suggest differences in SSPLs between urban and rural areas. Findings of empirical studies on the geographies of subjective well-being are inconclusive (Dolan et al. 2008). Differences in expectations regarding the minimum income can be attributed to differences between area types, which can include differences in price levels between rural and urban areas (Janský and Kolcunová 2017); and differences in labour market opportunities (Shucksmith et al. 2009). As further argued by Shucksmith et al. (2009), richer EU countries experience lower levels of evidence of urban-rural differences than poorer ones. Our findings suggest no clear pattern in the differences in SSPLs between rural and urban areas between different parts of the EU. In accordance with Dolan et al. (2008), we argue that the phenomenon is far too complex to make a clear distinction between different types of areas in terms of population size and density. 


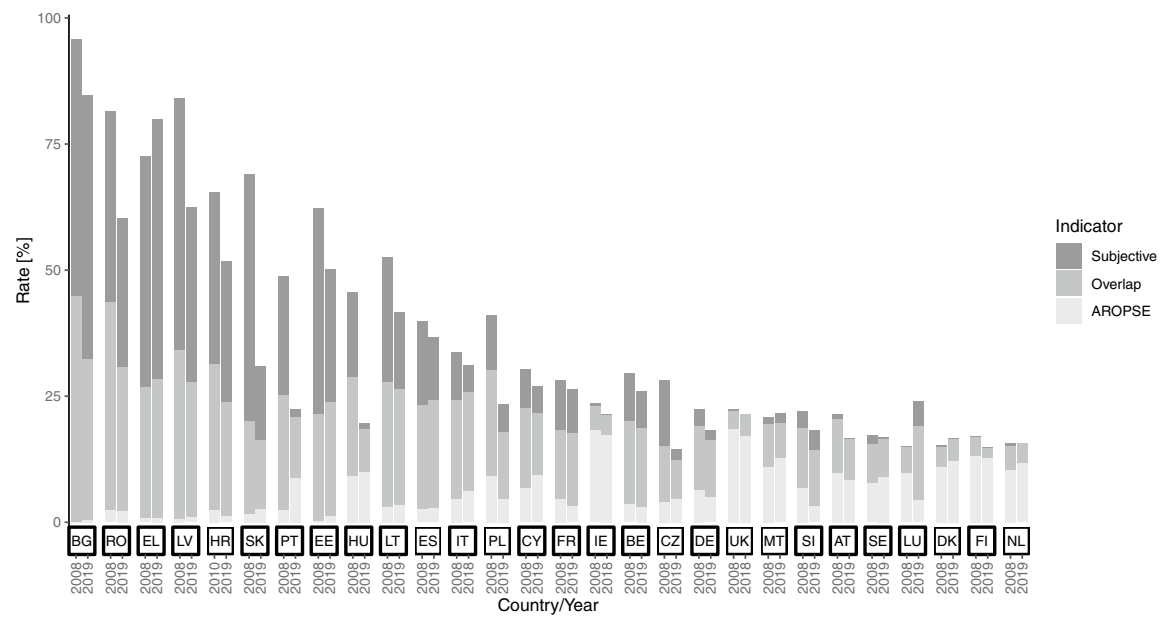

Fig. 4 Overlap between the official at-risk-of-poverty-or-social-exclusion (AROPSE) and subjective poverty indicators. Notes: The lightest parts of the bars represent the shares of individuals who are officially (AROPSE) poor, but not subjectively poor. The darkest parts represent shares of individuals who are subjectively poor, but not officially poor. The grey parts between light and dark parts of the bars represent the overlap, i.e. individuals who are both officially and subjectively poor. Source EU-SILC 2008 and 2019 (2018). Authors' computations

A comparison between subjective and purely objective poverty status would be a natural further step in assessing the necessity of including subjective poverty as a supplementary indicator to the objective poverty levels. Since no official objective income poverty thresholds are defined in the European Union (see, e.g. the discussion by Bradshaw and Mayhew 2011), we conducted a comparison between subjective poverty and the official multidimensional poverty indicator tracked in the EU. Our findings suggest that, for the majority of countries, subjective poverty contains additional information which could be useful to policymakers assessing poverty levels and designing anti-poverty tools. From the perspective of changes over time, it is particularly interesting to observe how the changes in the combination of the official multidimensional poverty indicator and subjective poverty are associated with the changes in subjective poverty rates. In some countries, the drop when the indicators are combined is associated with a remarkable decline in the share of households that are subjectively poor but not officially poor, while in other countries this is not the case. We find this alternative indicator of at risk of poverty or social exclusion (based on 4 dimensions) particularly important, since it contains an additional dimension of poverty not captured by the official indicators.

\section{Implications and Suggestions for Future Research}

In this section, we discuss the potential implications of our findings for future research in the field of subjective poverty. We primarily focus on two aspects: 1. 
implications for estimation techniques; and 2. implications for the relationships between subjective and objective poverty.

The traditional intersection approach relies on employing OLS regressions, assuming that minimum income is an increasing, concave function of actual income (de Vos and Garner 1991). We compare the OLS estimations to results based on Local Polynomial Regression Fitting (LOESS), which is a generalisation of moving average and polynomial regression. LOESS fits simple models to localised subsets of data to build up a function that describes the deterministic part of the variation in data, point by point, i.e. it is not a priori required to specify a global function of any form to fit a model to the data (Heckert et al. 2002). Although this technique cannot be used to find the intersection analytically, it can be employed to find the threshold computationally. Estimations based on LOESS regressions suggest a curvilinear relationship between the subjective minimum and actual income. In addition, for the majority of countries, these estimations suggest inconsistencies for low values of actual income. Specifically, the fitted values of subjective minimum income based on LOESS differ considerably from the fitted values based on OLS (Fig. 5). This may be a consequence of high variability in responses to the MIQ for low levels of income, which makes the estimations noisy.

Nonetheless, these deviations do not significantly affect the intersection point. In addition, both estimation techniques suggest that, for high values of actual income, the corresponding subjective minimum income curve is asymptotically approaching a certain level. It might be interesting for future research to examine what kind of income aspirations this amount represents. Another potential implication for future research can include examining different estimation techniques and assessing their advantages and disadvantages in this type of empirical research.

The next implication is related to the relationship between subjective minimum income and objective poverty. Although there is nothing like an official objective poverty line in the European Union, individual member states implement laws on material need assistance. Individuals living in households under certain income thresholds are eligible for various forms of social benefits. These thresholds can, to some extent, be thought of as proxies for national absolute poverty lines.

We will demonstrate this idea using Slovakia and Czechia as country case studies. ${ }^{6}$ In Slovakia, the subsistence minimum income for a household of two adults and two dependent children was defined as approximately $520 \mathrm{EUR} / \mathrm{month}$ between July 2017 and June 2018. In Czechia, the amount was approximately 390 EUR/ month for a similar household in 2018.

The 2018 data (Fig. 6) suggests that the minimum monthly income required by the poorest (in monetary terms) Slovak households of two adults and two dependent children are, on average, very close to the official amounts of subsistence income. Czech low-income households require a similar minimum income, although the

\footnotetext{
${ }^{6}$ National laws on eligibility for social assistance are very diverse and differ considerably across countries. We use the country case studies as a simplified demonstration only, without any intention to draw conclusions. We arbitrarily chose Slovakia and Czechia since the eligibility criteria are defined in terms of monthly income and due to the knowledge of the national contexts by two of the authors.
} 


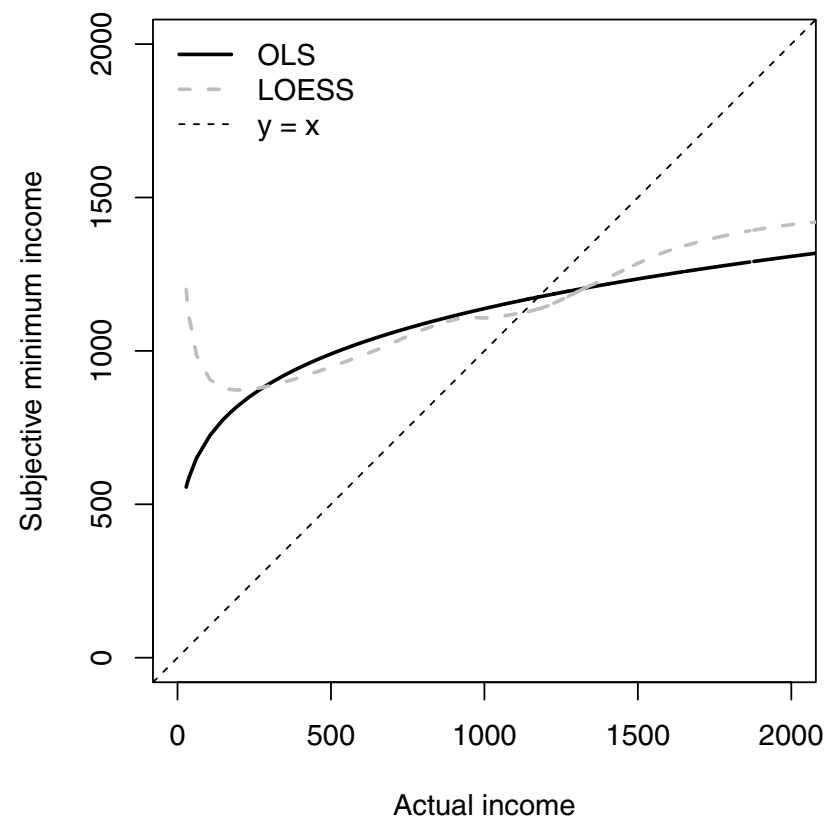

Fig. 5 An illustration of the OLS vs LOESS estimation. Source EU-SILC 2018. Authors' computations

subsistence levels are set at lower amounts. We have noted that the variability in responses to the Minimum Income Question is relatively high, which can make the estimations somewhat noisy. Note that this observation is based on a case of two countries at one point in time, and should be interpreted very cautiously. In order to fully understand this relationship, further research would be necessary.

\section{Concluding Remarks}

In this study, we argue that subjective poverty indicators provide essential information and should be taken into account as a supplementary dimension for assessments of the poverty level in a society. Governmental policies have significant impacts on people's lives, which may not be fully captured by official statistics. Trends in subjective poverty may reflect changes in societies and ultimately complement these indicators. We believe that results reported in this study can serve as a useful source of information on subjective poverty perceptions in the EU, which are important for researchers, and even more so for policymakers relying on official statistics, which traditionally do not include such data.

This paper contributes to the existing literature on poverty by re-examining its subjective dimension, which has been somewhat neglected since the 1990s. Our aim is not to uncover deeper relationships between subjective poverty and other socioeconomic phenomena, but rather it is purely empirical-to present the current situation regarding subjective poverty in the European Union. We also examine trends in 


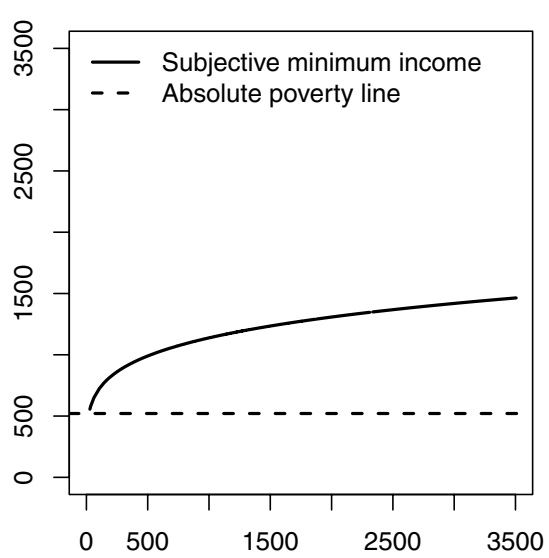

Actual income

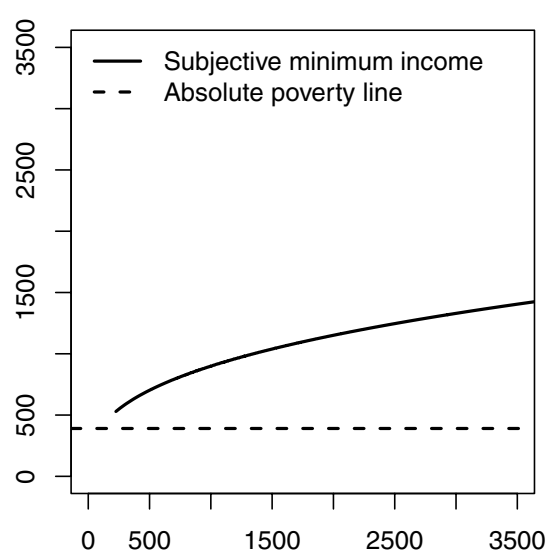

Actual income

Fig. 6 Subjective minimum income and absolute poverty line (left: Slovakia; right: Czechia; 2018). Source EU-SILC 2018. Authors' computations

subjective poverty over the past $10-16$ years. We believe that this study is primarily useful for social scientists focussing on quality-of-life issues, and for policymakers seeking data on different aspects of poverty.

Estimations in this paper are based on a standard methodology, and we are aware of drawbacks, including a high level of variation in the key variables. However, we believe that this study can contribute to re-opening more vibrant and intensive discussions related to the study of subjective poverty. The approach used in this paper originated in the 1970s, and econometric methods have undergone considerable developments since then. Our next goal will be to conduct a comparative study to assess the robustness of trends in subjective poverty based on different (non-parametric and semi-parametric) techniques.

We hope that this study may serve to inspire other social scientists interested in uncovering potential factors in changes in subjective poverty rates. These may include factors related to the adoption of the euro-currency, impacts of economic crises, and other potentially important events in the EU and its individual countries. Here, we have attempted to cautiously outline some of these events. Nonetheless, we believe that in order to comprehensively study relevant factors, implementation of rigorous econometric techniques allowing researchers to separate out various external factors is necessary. This is beyond the scope of this study.

Supplementary Information The online version contains supplementary material available at https://doi. org/10.1057/s41287-021-00457-2.

Acknowledgements The work of Tomáš Želinský and Martina Mysíková was supported by the Czech Science Foundation under Grant no. 18-07036S "Methodology and reality of poverty: Czech Republic in the European context". Tomáš Želinský further acknowledges support from the Slovak Scientific Grant Agency (grants VEGA 1/0453/19 and VEGA 2/0002/19). The EU-SILC datasets were made available on the basis of contract no. 247/2019-EU-SILC-HBS between the European Commission, Eurostat, and the Institute of Sociology of the Czech Academy of Sciences. We are further grateful to comments and 
feedback provided by the participants of the United Nations Economic Commission for Europe (UNECE) Expert Meeting on Measuring Poverty and Inequality held in Geneva (5-6 December 2019). The responsibility for all conclusions drawn from the data lies entirely with the authors.

Disclaimer The views expressed in this study, including those related to statistical, methodological, technical, and operational issues, are solely those of the authors. The authors accept responsibility for all errors.

\section{Declarations}

Conflict of interest The authors have no actual or potential conflict of interest including any financial, personal, or other relationships with other people or organisations within three years of beginning the submitted work that could inappropriately influence, or be perceived to influence, their work.

Open Access This article is licensed under a Creative Commons Attribution 4.0 International License, which permits use, sharing, adaptation, distribution and reproduction in any medium or format, as long as you give appropriate credit to the original author(s) and the source, provide a link to the Creative Commons licence, and indicate if changes were made. The images or other third party material in this article are included in the article's Creative Commons licence, unless indicated otherwise in a credit line to the material. If material is not included in the article's Creative Commons licence and your intended use is not permitted by statutory regulation or exceeds the permitted use, you will need to obtain permission directly from the copyright holder. To view a copy of this licence, visit http://creativecommons.org/licen ses/by/4.0/.

\section{References}

Bertrand, M., and S. Mullainathan. 2001. Do people mean what they say? Implications for subjective survey data. The American Economic Review (papers and Proceedings) 91 (2): 67-72.

Bishop, J.A., A. Grodner, H. Liu, and I. Ahamdanech-Zarco. 2014. Subjective poverty equivalence scales for Euro Zone countries. The Journal of Economic Inequality 12 (2): 265-278.

Bradshaw, J., and E. Mayhew. 2011. The measurement of extreme poverty in the European Union. Brussels: European Commission.

Chakravarty, S.R., and J. Silber. 2008. Measuring multidimensional poverty: The axiomatic approach. In Quantitative approaches to multidimensional poverty measurement, ed. N. Kakwani and J. Silber. London: Palgrave Macmillan.

Chan, S.M., and H. Wong. 2020. Impact of income, deprivation and social exclusion on subjective poverty: A structural equation model of multidimensional poverty in Hong Kong. Social Indicators Research 152 (3): 971-990.

Colosanto, D., A. Kapteyn, and J. van der Gaag. 1984. Two subjective definitions of poverty: Results from the Wisconsin Basic Needs Study. Journal of Human Resources 19 (1): 127-138.

Cracolici, M.F., F. Giambona, and M. Cuffaro. 2012. The determinants of subjective economic wellbeing: An analysis on Italian-Silc data. Applied Research in Quality of Life 7 (1): 17-47.

Danziger, S., J. van der Gaag, M.K. Taussig, and E. Smolensky. 1984. The direct measurement of welfare levels: How much does it cost to make ends meet? The Review of Economics and Statistics 66 (3): $500-505$.

de Vos, K., and T.I. Garner. 1991. An evaluation of subjective poverty definitions: Comparing results from the U.S. and the Netherlands. Review of Income and Wealth 37 (3): 267-285.

Deaton, A., and A.A. Stone. 2013. Two happiness puzzles. The American Economic Review (papers and Proceedings) 103 (3): 591-597.

Deleeck, H., and K. van den Bosch. 1992. Poverty and adequacy of social security in Europe: A comparative analysis. Journal of European Social Policy 2 (2): 107-120.

Diener, E., E.M. Suh, R.E. Lucas, and H.L. Smith. 1999. Subjective well-being: Three decades of progress. Psychological Bulletin 125 (2): 276-302. 
Dolan, P., T. Peasgood, and M. White. 2008. Do we really know what makes us happy? A review of the economic literature on the factors associated with subjective well-being. Journal of Economic Psychology 29 (1): 94-122.

European Commission. 2010. Communication from the Commission: Europe 2020. A strategy for smart, sustainable and inclusive growth. Brussels, European Commission. [COM(2010) 2020 final].

European Commission. 2020. Social situation monitor: Research findings. Brussels: European Commission: Directorate-General for Employment, Social Affairs and Inclusion.

European Council. 2010. Cover note from general secretariat of the council to delegations: Conclusions. Brussels, European commission. [EUCO 13/10].

Flik, R.J., and B.M.S. van Praag. 1991. Subjective poverty line definitions. De Economist 139 (3): 311-330.

Foster, J., J. Greer, and E. Thorbecke. 1984. A class of decomposable poverty measures. Econometrica 52 (3): 761-766.

Foster, J., J. Greer, and E. Thorbecke. 2010. The Foster-Greer-Thorbecke (FGT) poverty measures: 25 years later. The Journal of Economic Inequality 8 (4): 491-524.

Garner, T.I., and K. Short. 2004. Economic well-being based on income, consumer expenditures and personal assessments of minimum needs. In Studies on economic well-being: Essays in the honor of John P. Formby, Vol. 12 of the Series Research on Economic Inequality, ed. J.A. Bishop and Y. Amiel, 319-361. Oxford: Elsevier Science.

Gerlach-Kristen, P., and S. Lyons. 2018. Determinants of mortgage arrears in Europe: Evidence from household microdata. International Journal of Housing Policy 18 (4): 545-567.

Goedhart, T., V. Halberstadr, A. Kapteyn, and B.M.S. van Praag. 1977. The poverty line: Concept and measurement. The Journal of Human Resources 12 (4): 503-520.

Heckert, N. A. et al. 2002. Handbook 151: NIST/SEMATECH e-Handbook of Statistical Methods. National Institute of Standards and Technology, U.S. Department of Commerce. https://www.nist. gov/publications/handbook-151-nistsematech-e-handbook-statistical-methods/. Accessed 17 Aug 2020.

Hagenaars, A., and K. de Vos. 1988. The definition and measurement of poverty. Journal of Human Resources 23 (2): 211-221.

Janský, P., and D. Kolcunová. 2017. Regional differences in price levels across the European Union and their implications for its regional policy. The Annals of Regional Science 58 (3): 641-660.

Kapteyn, A., P. Kooreman, and R. Willemse. 1988. Some methodological issues in the implementation of subjective poverty definitions. The Journal of Human Resources 23 (2): 222-242.

Lane, R.E. 1991. The market experience. Cambridge: Cambridge University Press.

Muffels, R., J. Berghman, and H.-J. Dirven. 1992. A multi-method approach to monitor the evolution of poverty. Journal of European Social Policy 2 (3): 193-213.

Mysíková, M., T. Želinský, T.I. Garner, and J. Večerník. 2019. Subjective perceptions of poverty and objective economic conditions: Czechia and Slovakia a quarter century after the dissolution of Czechoslovakia. Social Indicators Research 145 (2): 523-550.

Mysíková, M., T. Želinský, M. Jirková, and J. Večerník. 2021. Equivalence scale and income poverty: Two approaches how to estimate country-specific scale for the Czech Republic. Social Indicators Research 156 (1): 21-45.

Pradhan, M., and M. Ravallion. 2000. Measuring poverty using qualitative perceptions of consumption adequacy. The Review of Economics and Statistics 82 (3): 462-471.

Ravallion, M. 1992. Poverty comparisons: A guide to concepts and methods. LSMS Working Paper No. 88. Washington DC: The World Bank.

Ravallion, M. 2014. Poor, or just feeling poor? On using subjective data in measuring poverty. In Happiness and economic growth: Lessons from developing countries, ed. A. Clark and C. Senik. Oxford: Oxford University Press.

Ravallion, M. 2016. The economics of poverty: History, measurement, and policy. Oxford: Oxford University Press.

Saunders, P., B. Halleröd, and G. Matheson. 1994. Making ends meet in Australia and Sweden: A comparative analysis using Subjective Poverty Line methodology. Acta Sociologica 37 (1): 3-22.

SPC. 2010. Cover note from the Social Protection Committee to Permanent Representative Committee: Europe 2020 Strategy-SPC Contribution. Brussels: Council of the European Union.

Shucksmith, M., S. Cameron, T. Merridew, and F. Pichler. 2009. Urban-rural differences in quality of life across the European Union. Regional Studies 43 (10): 1275-1289. 
Simonsohn, U. 2018. Two lines: A valid alternative to the invalid testing of U-shaped relationships with quadratic regressions. Advances in Methods and Practices in Psychological Science 1 (4): 538-555.

Stiglitz, J. E., A. Sen, and J.-P. Fitoussi. 2009. Report by the commission on the measurement of economic performance and social progress.

Tharp, D.T., et al. 2020. Financial satisfaction and homeownership. Journal of Family and Economic Issues 41 (2): 255-280.

van Praag, B.M.S. 1968. Individual welfare functions and consumer behaviour. Amsterdam: North Holland Publishing Co.

van Praag, B.M.S., P. Frijters, and A. Ferrer-i-Carbonell. 2003. The anatomy of subjective well-being. Journal of Economic Behavior \& Organization 51 (1): 29-49.

van Praag, B.M.S., A.J. Hagenaars, and H. van Weerden. 1982. Poverty in Europe. Review of Income and Wealth 28 (3): 345-359.

Veenhoven, R. 2002. Why social policy needs subjective indicators. Social Indicators Research 58 (1-3): 33-46.

Vogel, J. 2002. Strategies and traditions in Swedish social reporting: A 30-year experience. Social Indicators Research 58 (1-3): 89-112.

Vrooman, C.J. 2009. Rules of relief; institutions of social security, and their impact. The Hague: The Netherlands Institute of Social Research.

Wang, H., Q. Zhao, Y. Bai, L. Zhang, and X. Yu. 2020. Poverty and subjective poverty in Rural China. Social Indicators Research 150 (1): 219-242.

Wong, C.K., K.Y. Wong, and B.H. Mok. 2006. Subjective well-being, societal condition and social policy-the case study of a rich Chinese society. Social Indicators Research 78 (3): 405-428.

Želinský, T., J.W.J. Ng, and M. Mysíková. 2020. Estimating subjective poverty lines with discrete information. Economics Letters 196: 109545.

Publisher's Note Springer Nature remains neutral with regard to jurisdictional claims in published maps and institutional affiliations. 